\title{
An Update on the Use of Modern Financial Instruments in the Insurance Sector
}

\author{
Ernst N. Csiszar \\ 1222 North Astor Street, Chicago, IL 60610, U.S.A. \\ E-mail: ernst.csiszar@yahoo.com
}

The world's financial markets have exploded with new products and new techniques such as derivatives and securitizations, giving rise to huge new markets. The author reviews recent developments in insurance-linked securities (ILS), financial products that link insurance and reinsurance with these new markets. Pricing and availability problems after Hurricane Katrina have led to newer types of products making their way into these markets. While catastrophe bonds still make up a significant portion of ILS, the risk of not recovering reinsurance receivables, for instance, can now be transferred to the financial markets via credit derivatives. Catastrophe risk can also be packaged as a credit derivative. New participants, like hedge funds and specialized mutual funds, have also caused a revival of exchange-traded ILS. Trading in catastrophe futures and weather derivatives is thriving. Sidecars were revived. Contingent capital is readily available. New perils, combined with others, are being covered. Insurance and reinsurance companies can no longer treat these instruments as a matter of relative pricing between traditional products and ILS. After Katrina, access to multiple sources of capital has become an essential strategic objective. The Geneva Papers (2007) 32, 319-331. doi:10.1057/palgrave.gpp.2510134

Keywords: insurance-linked securities; derivatives market; credit derivatives; catastrophe bonds; reinsurance receivables; corporate strategy

\section{Introduction}

Financial markets are experiencing an explosion of innovation that started in the early 1980s and continues through today. While raising capital through stocks and bonds is still important to these markets, that activity has nearly become a sideshow. The trading of stocks and bonds has been overtaken by trading in derivatives and in securitized instruments. Derivatives are complex financial instruments that "derive" their value from some other underlying asset or index, while securitized instruments transfer a risk unwanted by one party to another party more inclined to take that risk. In combination, derivatives and securitized instruments have created huge new markets and new opportunities for issuers, investors, and intermediaries alike.

Many industries were quick to understand and use these new instruments to their advantage. Financial institutions in particular were quick to grasp the benefits from, say, bundling and transferring mortgages into the financial markets or from selling a credit derivative by splicing the credit risk from the interest rate risk on a bond. On the other hand, insurance and reinsurance companies were off to a slow start. While some insurance companies seemed to be interested in exploring and experimenting with some of these new instruments, most were reluctant to commit significant resources to 
developing insurance-linked products suitable for these new markets. Of late, that attitude seems to have changed.

Insurance-linked securities (ILS) stand at the intersection between insurance and the financial markets. ILS transform insurance risks typically retained by insurers or reinsurers into risks that are generally handled by the financial markets. They are an indicator of the convergence that is taking place between these two economic sectors. Talk of convergence between insurance and financial markets dates back several decades. As mentioned earlier, at its inception, the process was slow and costly. It took Mother Nature to kick it into high gear in 2005.

Taken on top of the five consecutive hurricanes to hit the American Southeast in the prior year, Hurricanes Katrina, Rita, and Wilma in 2006 were transformational. The defining event was really Hurricane Katrina. Katrina came as a great shock to the insurance industry. While the storm was geographically confined to portions of the southeastern United States, its impact on the industry spanned the entire non-life sector. ${ }^{1}$ For purposes of this paper, what is of importance is that the Katrina catastrophe seems to have reawakened the industry's interest in the vital role that ILS can play in a firm's capital structure. More than just a reawakening, the evidence points to a sea-change in how this industry values and employs these instruments in its broader business strategies.

The remainder of this paper is devoted to a discussion of links between insurance and the financial markets. Much has been written about the subject ${ }^{2}$ and we do not intend to provide a comprehensive review of all the developments that have taken place over the years nor do we intend to write an introduction to the subject of ILS. Instead, our aim is more in the nature of an update with respect to developments that have taken place within the last few years, for much has happened and much is happening particularly since Katrina. Accordingly, while we begin with an overview of the more significant issues shared between derivatives and securitizations in general and ILS, we intend to confine ourselves mostly to recent developments specific to ILS.

\section{The world of modern financial instruments}

Today's financial markets bundle and unbundle, package and repackage, retain and transfer economic and financial risks with great flexibility and imagination. Interest rate swaps between banks give birth to foreign currency derivatives between the banks' clients, which in turn result in the development of forward contracts and swap contracts for the energy sector. Bundling mortgages into mortgage-backed securities (MBS) gives rise to other asset-backed instruments (ABS) which in turn lead to the unbundling and securitization of credit risk from market risk in the bond market (e.g., $\mathrm{CDO}$ and $\mathrm{CDS}$, collateral debt obligations and credit default swaps). Financial

\footnotetext{
${ }^{1}$ This paper limits itself to a discussion of financial instruments in the context of the non-life segment of the insurance industry. We do not propose to discuss recent activities on the life side such as the recent spate of Triple $X$ reserve securitizations and embedded value transactions.

${ }^{2}$ For excellent overviews of the entire subject matter of insurance-linked securities, see Lane (2002); Banks (2004); or Culp (2006).
} 
engineering has become all the rage and the "quant", who brings his mathematical talent to bear upon developing these new financial instruments, has become a valued addition to Wall Street's workforce.

Innovation has its price, however. The complexity of these new products and techniques does raise concerns regarding the potential for new or additional economic and financial risks to be introduced into the world's financial markets, risks that may be very difficult to understand and may lack the degree of transparency necessary for the market to work efficiently. Wherever and whenever these instruments have been introduced, they have had impact on valuations; they tend to change the market's velocity; they impact its volatility, affect its overall liquidity, and tend to introduce additional leverage. Whether or not that is good or bad remains subject to a lively debate. ${ }^{3}$ Regardless of which side one takes in this debate, one fact remains: the wide dissemination of these products and techniques has significantly broadened the basket of risk management tools available to all manner of businesses, including insurance and reinsurance.

How widely have these new instruments been disseminated? Well, the public seems to have an unlimited appetite for these new products. This segment of our financial markets has come to overshadow the traditional trading in debt and equities by several degrees of magnitude. The total market capitalization of the world's stock markets is about $\$ 41$ trillion. The gross domestic product (GDP) of the United States, Canada, the European Union, Japan, and China combined amounted to \$34 trillion in 2006. Now consider this: the total notional value of swaps and derivatives for last year was $\$ 327$ trillion. ${ }^{4}$ The fastest growing segments of financial markets are CDS and equity derivatives. The enormity and the speed at which these new markets are developing are quite frankly almost incomprehensible. A decade ago, no one had heard of a CDS. Last year, the notional principal outstanding volume of CDS was $\$ 34.5$ trillion. Five years ago, no one had heard of equity derivatives. A total of $\$ 7.2$ trillion in notional amounts were outstanding last year.

\section{ILS in general}

Given these eye-popping numbers, it should come as no surprise that the insurance and reinsurance sector is taking a closer look at these instruments. Last year's volume

\footnotetext{
${ }^{3}$ After his own bitter experience with unwinding Gen Re's derivatives portfolio, Warren Buffet has regularly issued missives drawing attention to the potential mischief that these instruments can cause. More recently, Jean-Claude Trichet, president of the European Central Bank, and Sir John Gieve, deputy governor of the Bank of England, both warned about the potential for systemic risk from the growing complexity of the derivatives market (see Financial Times (2007b, p. 6)). Others reject that warning and point to the positive role that these instruments bring to the market through a stabilizing effect. See, for instance, Steil (2006, p. 13). The truth of the matter is that FAS 133, the U.S. accounting standard, leads to significant earnings volatility, even though there appears to be nothing intrinsically wrong with derivatives.

${ }^{4}$ While notional values overstate the amount at risk, ISDA estimates that gross credit exposure before netting amounts to $\$ 8.8$ trillion, and credit exposure after netting is estimated at $\$ 1.6$ trillion (see ISDA (2007)).
} 
of new issues in non-life ILS - about $\$ 4.7$ billion - exceeded the previous year's volume by over 100 per cent. Total volume of outstanding non-life ILS is estimated at over $\$ 8$ billion. Hedge funds contributed another $\$ 10$ billion in 2006 through industry loss warranties (ILW), ${ }^{5}$ sidecars, and investments in cat bonds. ${ }^{6}$ While still quite small, these numbers also reflect a measure of the potential opportunities that lie ahead. Only a very small percentage of the potential overall market has been tapped ${ }^{7}$ and there is room for significant growth.

There are three broad categories of risk transfer between insurance and financial markets:

(1) derivatives, in the form of options, swaps, futures, forward contracts, and weather derivatives;

(2) securitizations, mostly in the form of cat bonds; and

(3) contingent capital structures for equity and debt.

Current indicators point to a pick-up of activity in every category. Some insurance experts maintain that this merely reflects a temporary phenomenon, caused by the reinsurance pricing issues that surfaced in the aftermath of Katrina. Historically, the pricing of reinsurance products has always had a significant impact on the demand for alternatives to reinsurance. In the past, high reinsurance prices caused companies to look around for alternatives. Soft markets drove them back to traditional reinsurance. This historical pattern is thought to be of particular significance now because pricing in the reinsurance market, including cat risk pricing, is again softening. There is reason to question, however, whether history, in this instance, is a reliable guide to what is likely to happen next.

Indeed, others maintain that more fundamental factors are at work and that conditions in the financial markets continue to favor ILS-related activities on a much more permanent basis. Recent evidence seems to confirm that view. While it is true that capacity shortages, availability, and pricing of reinsurance were the initial "flaps of the butterfly's wings" that set the convergence process into high gear, this time there seems to be more at work here than that. If one listens to the investment banking community and to investors, for instance, there certainly appears to be a new attitude that has taken a hold. Many of them showed not the slightest of interest in ILS in years past. Now, many of them view insurance and reinsurance as the most fertile and most promising new field for exploiting new opportunities. No doubt the splendid profits of last year help the cause. But even with at least one cat bond in trouble, ${ }^{8}$ there is every

\footnotetext{
${ }^{5}$ Industry loss warranties have become a popular investment vehicle for hedge funds. While in reality nothing more than a reinsurance contract, the financial markets' participation qualifies them as securitized instruments. Most ILW depend on a double trigger: the insured's losses and the industry loss based on an external measure (McDonnell (2002, Chapter 4)). Swiss Re estimates that hedge funds invested as much as \$4 billion in ILW in 2006.

${ }^{6}$ See Financial Times (2007a, p. 2).

${ }^{7}$ Swiss Re estimates that capital market activities represent only about 6 per cent of non-life reinsurance cover for 2006. Their study expects the cat bond market alone to grow to $\$ 30-\$ 44$ billion (see Swiss Re (2006)).

${ }^{8}$ Payments for losses from Katrina are expected to deplete Kamp Re's collateral (see Lumley (2007, p. 32)).
} 
reason to believe that these new investors and deal makers will continue their involvement. The beast needs to be fed: on Wall Street access to a new lending base will always generate new deals. What had been a lackluster reception for ILS by investors, originators, regulators, and various intermediaries in the years past, has turned into exuberant enthusiasm and anticipation for new breakthroughs in insurance-linked product and service offerings. The enthusiasm is not without foundation. ${ }^{9}$ Moreover, investment banking firms and hedge funds are making significant new investments in technology and in scientific and insurance expertise that is specifically tailored to this segment of the market. There is now a much broader investor base, including new specialty firms and hedge funds, and mutual funds. ${ }^{10}$ The deals, while more sizable, have also become smaller as a percentage of the larger market. Even very complex deals are easily absorbed by the market. ${ }^{11}$ The market has extended significantly beyond just cat bonds. Hannover Re, for instance, recently launched the first synthetic CDO of insurance and reinsurance companies. ${ }^{12}$ The market demonstrated significant liquidity and resilience even after all the hurricanes in 2004 and 2005. ${ }^{13}$ Deal structure in many cases (e.g., cat bonds) has become pretty standardized. Spreads have narrowed and transaction costs have come down. At the same time, rating agencies and insurance regulators have shifted from the traditional standard for judging financial resilience of a 1-in-100-years event to a more onerous 1-in-250-years standard, reflecting the need for a much higher level of balance-sheet protection in the future. Moreover, the National Association of Insurance Commissioners (NAIC) in the United States is actively considering the inclusion of cat risks as a separate category in determining a firm's risk-based capital.

All of these factors point to the need for insurance and reinsurance firms to gain a greater familiarity with these new financial instruments and methodologies and a deeper understanding and appreciation for their intrinsic value in transferring, neutralizing, and managing risks. What was once treated as a relative pricing decision between traditional catastrophe reinsurance and a catastrophe bond ("cat bond"), for instance, should turn into a more strategic recognition regarding the usefulness of having multiple sources of finance for one's balance sheet. ILS are strategic in nature. They provide the firm with diversification in managing its sources of capital on its balance sheet. Having more than one spigot on standby for additional capital is a good strategy in times hard as well as in times soft.

As mentioned earlier, post-Katrina there has also been the recognition that perhaps not enough balance-sheet protection had been purchased in the first place. In addition to the new rating agencies resilience requirements, and perhaps the new adjustments to the NAIC risk-adjusted capital measurements, for many companies newly recalibrated exposure models also reflect much higher risk accumulations and concentrations than previously thought. It is easy to forget that, as recently as the late 1980s, common

\footnotetext{
${ }^{9}$ For case descriptions of some of the more recent ILS activities, see Culp (2006, pp. 487-522).

${ }^{10}$ Bank Leu, for instance, launched a mutual fund specializing in cat bonds (see Banks (2004, p. 117)).

11 ABN Amro London and Catlin Group Limited, for instance, launched a highly complex natural catastrophe CDO in late 2006 (see Catlin Group (2006)).

12 See Societe Generale Corporate and Investment Banking (2007).

${ }^{13}$ The market took even Kamp Re's "bad news" in stride.
} 
wisdom in the industry held that a $\$ 5$ billion natural event was highly unlikely, while a $\$ 10$ billion event was beyond the realm of the possible. While the industry is still counting the losses from Katrina, we now do know that the storm has cost the industry at least $\$ 40$ billion in losses - and these could go much higher, to as much as $\$ 55$ billion if certain legal issues, mostly related to wind vs. water damage, are not resolved in the industry's favor. While most companies managed to survive the disaster with their balance sheets bruised but relatively intact, others had significant percentages of their surplus wiped out.

As much of a surprise as the sheer size of the damage is the fact that the relatively mild winds of the storm destroyed so much capacity. ${ }^{14}$ While the industry has managed to raise significant amounts of new capital and has produced stellar profits in 2006 , there is still a large gap between pre- and post-Katrina industry surplus. The relatively calm hurricane season of 2006 should not be taken with too much complacency. The prognosis for 2007 is once again for a very active weather pattern, and issuers and investors alike should well remain mindful of the fact that one quiet season does not make a trend. Besides, if one is to believe the pundits, more permanent climatological changes in underlying weather patterns lie ahead. According to these experts, the probabilities for increasingly severe weather patterns in a variety of different parts of the world are high for decades to come.

There is another dynamic at work with ILS that is worthy of note. The industry is under ever-increasing pressure to employ its capital more efficiently. With rare exceptions, insurers and reinsurers have been among the most anemic producers of shareholders' returns, with low single-digit ROEs often the norm. One has to wonder whether such poor performance is tied to the industry's closed business model. Most firms concentrate on how much to retain, how much to cede, and how much to retrocede while all the while the risk just gets passed around as if among incestuous cousins. ILS are also a breath of fresh air: they bring the outside in. New thought processes, new customer service standards, and new expectations from other sectors of the financial industry should be welcome. They will make some of the more sloppy business practices much harder to maintain. Take, for instance, the common practice by mutual agreement between insurer and reinsurer of making up a shortfall in reinsurance premiums in 1 year with premium increases in the years that follow. The message here is very clear: "it's OK to make a mistake in pricing". Financial markets tend to show little or no tolerance for such "back scratching" behavior. A firm that misprices its product in the financial markets is likely to find itself at the mercy of a competitor who gets it right - and gets it right from the start.

Historically, our industry has suffered from a lack of competition from outside its boundaries. ILS will, of necessity, change that. New financial competitors, who understand the discipline and the expectations of an efficient financial market, are changing "the rules of the game". Much like U.S. auto manufacturers when confronted with new Asian production and service techniques, and much like our other financial institutions like banks, savings and loan companies and mortgage firms

\footnotetext{
${ }^{14}$ Estimates now place the winds into Category 2 or 3 at most when the storm hit land. One can only imagine what the damage might be if a Category 5 storm were to hit a densely populated area.
} 
that have been forced to change, the increasing use of ILS will likely transform our current business models. One way in which the other financial firms have managed to achieve the expected returns was by relying less and less on retaining risks. Simply look at the success of their ABS. Our industry seems to focus rather narrowly on buying, holding, or ceding risks within the limited confines of insurance and reinsurance. This strategy however has been an unreliable and volatile driver of performance for our industry and those who invest in it. In years to come, insurers and reinsurers will find it harder and harder to justify this sort of outcome.

\section{The structure of ILS}

The task of transferring insurance risks from balance sheet to off-balance sheet is not a simple one however. There is at least one major difference between insurers and other types of financial institutions in the manner in which these risks can be managed or transferred. Insurance is an industry that is highly regulated. Only a licensed insurance company can sell a policy, for instance. Once sold (the rare exception being a novation, and statutes of limitation aside), the selling company remains liable to the policyholder regardless of any possible risk transfer to another entity. A bank can sell a loan and rid itself of that risk entirely. An insurance company, on the other hand, can only in the rarest of instances sever its bonds with its policyholders completely. The first observation about structure, therefore, is that an insurance-linked transaction will always require an issuing insurer to retain the risks it assumes from its policyholders. It can find ways to indemnify itself; it can seek to hedge these risks; it might even speculate for profit from these risks. But, unlike a bank or a mortgage institution, it can never fully divorce itself from the risks that it underwrites.

From a conceptual standpoint, ILS has many of the characteristics of a corporate bond. A willing investor provides capital. A specified event triggers a loss with the consequence that the investor loses all or part of his capital. What differentiates an ILS from a typical corporate bond is the nature of the triggering event, the perils covered, the nature of the trigger itself, and the amount of capital exposed to the loss. Otherwise, loss performance is typically analogous to a high-yield non-investment grade corporate bond such as a BB-rated one. Spreads tend to average at around 500 basis points, though lately they have narrowed somewhat.

\section{Insurance-linked derivatives}

The term "derivative" refers to a financial instrument that derives its value from an underlying market reference, be it an asset, a liability, or some type of index. The reference can be real (i.e., the assets appear on the balance sheet of the issuing firm) or it can be "synthetically" created without the transfer of full ownership to an issuer. Derivatives can be traded on an exchange or they can be traded privately. In the latter case, they are said to be traded over-the-counter (OTC).

Unlike insurance contracts, which require an insurable interest and an indemnification, derivative contracts can be used to speculate for profit as well as to protect the downside of a risk by hedging. In theory, at least, an insurance or reinsurance 
company can design a perfect hedge for its entire portfolio of insurance risks through a combination of differently designed derivatives. In practical terms, of course, a derivative always exposes the company to some basis risk - the possibility that the derivative payout will differ from the actual loss. The basis risk problem is further aggravated by the fact that insurance risks tend to defy the assumptions of the BlackScholes option pricing model. Distributions with "fat tails", for instance, are a common sight in assessing insurance exposures, especially cat exposures. ${ }^{15}$

There are two fundamental types of derivatives: options and forward contracts. Other instruments result from the rich variety of instruments that can be derived from combining different elements of the two. Hence, the market trades in futures, futures options, and a variety of different types of swaps. ${ }^{16}$

Interestingly enough, one area of ILS that is experiencing considerable momentum is on the exchanges. Most of us will recall that the development of a public market for exchange-traded insurance derivatives has been slow in the making. In fact, early efforts by the Chicago Board of Trade (CBOT) to make a market in exchange-traded catastrophe derivatives had to be abandoned for lack of interest. Activity on the Bermuda Commodities Exchange (BCOE) and the New York Catastrophe Risk Exchange (CATEX) was not much better. However, in recent years - post-Katrina there has been a resurgence of activity in this segment of the market. Weather derivatives, for instance, have become an accepted way to hedge temperature, waterflow, snowfall, precipitation, wind, and humidity exposures for a variety of different buyers, ranging from energy companies, to farmers, and to amusement parks. ${ }^{17}$ The Chicago Mercantile Exchange (CME) now makes an active market for futures and futures options on temperature indexes in 18 American, nine European, and two Japanese cities. Contracts based on temperature, snowfall, and frost indexes for 35 cities worldwide are available and actively traded. In early 2006, the CME added a snowfall futures and options product, and a new futures product for frost days. Under consideration for future product launches are derivatives relating to evacuation risk, hurricane risk, and precipitation risk. In an economy such as the United States', as much as 30 per cent is estimated to be subject to weather risk; and, hence, the market's ten-fold growth over the past 2 years should come as no surprise. As of June 2006, the average daily volume in weather derivatives on the CME reached $\$ 45$ billion in nominal value.

More recently, the New York Mercantile Exchange (NYMEX) announced the resumption of trading in catastrophe options and futures, the very same types of products that the CBOT discontinued in 2000. Investors appear to be interested, but it is too early to make any forecasts regarding volume. Icap, the inter-dealer broker, and insurance broker Jardine Lloyd Thompson have also announced the launch of new cat derivatives products. In February 2007, the CME also announced a joint CME-

\footnotetext{
${ }^{15}$ See Krutov (2006).

${ }^{16}$ For an excellent review of the different varieties of derivative instruments, see Culp (2006, Parts 2 and 3).

${ }^{17}$ Weather derivatives are index based with the stipulation that a temperature, precipitation level, or other weather-related index triggers a payoff. No proof of economic loss is required. OTC transactions are also available. Insurance companies take advantage of these instruments by selling off weather-related risks via these derivatives.
} 
Carvill Group hurricane index futures and options contracts on its Globex electronic exchange.

The OTC market for insurance derivatives has also become much more active in the last few years. Combinations of derivatives have gained momentum. For instance, a weather derivative for frost days, in combination with a futures contract for orange juice, can protect an orange grower and his insurer from ruin. A swap of Japanese earthquake risk for a combination of North Atlantic hurricane and European windstorm risks can make sense. ${ }^{18}$

The creation and design of derivatives is limited by human creativity and imagination only. Derivatives, by their very nature, can be adapted to any class of assets or liabilities - whether liquid, leveraged, real, or synthetic. For instance, ILW essentially options triggered by reaching a certain level of aggregated industry-wide losses - have become the darlings of certain hedge funds. Early 2007 also saw the creation of a market maker in ILW. Deutsche Bank launched a standardized derivative contract for U.S. hurricanes and earthquakes called an Event Loss Swap (ELS). ${ }^{19}$ Coverage is available for all U.S. jurisdictions. With no need to engage in bilateral negotiations, such as those encountered in the OTC market, a buyer of ELS can now pay a premium for protection from industry-wide losses of certain magnitudes, as verified by an independent loss assessment firm. Threshold levels for earthquakes are set at $\$ 10$ and $\$ 15$ billion, and $\$ 20, \$ 30$, and $\$ 50$ billion for hurricanes and tornadoes. ELS contracts are akin to $\mathrm{CDS} .^{20}$

Along similar lines, in late 2006, ABN Amro and Catlin announced their Bay Haven Limited transaction, the first public structured investment in a pool of ILW for a mix of perils. ${ }^{21}$ It is structured as a CDO of natural catastrophe risk. The issue is the first ever publicly rated $\mathrm{CDO}$ of such risk. The deal covers a 3-year period of perils consisting of U.S. hurricanes (Florida, Gulf States, and East Coast), California earthquakes, New Madrid (Midwestern U.S.), UK windstorms, European windstorms, Japanese typhoons, and Japanese earthquakes. Its structure involves two tranches of senior secured floating rate notes, rated $\mathrm{AA}$ and $\mathrm{BBB}$, respectively. The transaction makes over $\$ 200$ million in coverage for six potential events available to Catlin with different parametric triggers for different events.

Progress is also being made on another front. Typically, reinsurance recoverables, after reserves, make up a large portion of a firm's balance sheet. Finding a way to transfer these recoverables off the balance has long been one of the objectives of financial engineering. Reaching that objective received a boost in December 2006 when Aspen announced a credit default structure that protects the firm against losses from its potential inability to collect reinsurance payments from its reinsurers. $^{22}$ The derivative instrument covers up to $\$ 420$ million and is rated AA.

\footnotetext{
${ }^{18}$ See, for instance, the Swiss Re and Tokio Marine transaction described in Culp (2006, p. 515).

${ }^{19}$ See Deutsche Bank (2006).

${ }^{20}$ In a CDS, one party pays the principal and another party makes periodic interest payments when credit default occurs.

${ }^{21}$ See footnote 11 .

${ }^{22}$ See Aspen Insurance Holdings Limited (2006).
} 
The 5-year-policy covers current and future reinsurance recoverables, with different credit-event triggers for different counterparties.

Taking the recovery of reinsurance receivables one step further, Hannover Re, through its Merlin CDO 1 structure, ${ }^{23}$ announced the first synthetic collateralized financial derivative for protection against widespread losses in the insurance and reinsurance industry. Through the use of a variety of different tranches and coupon rates, Merlin CDO 1 will pay Hannover Re if and when a certain number of insurance and reinsurance companies out of a pool of 100 suffer an adverse credit event such as bankruptcy, insolvency, and inability to pay. ${ }^{24}$ The deal has a nominal value of 1 billion euros in four differently rated tranches. Interestingly, the deal also brought a new set of European and Asian investors into the ILS sector.

\section{Insurance-linked securitizations}

Portfolio theory suggests that the pooling of assets or liabilities from a multiplicity of different sources would stabilize the risk profile of the pool for investors. That is the idea behind a securitization. Pools of assets such as mortgages, loans, receivables, and leases are typical. But any asset that produces cash flows can in theory be securitized. ${ }^{25}$ ABS have been in vogue for several decades. The volume of newly issued ABS reached \$2 trillion in 2006. More recently, financial markets have taken an interest in securitizing credit market risks with a variety of pooling methodologies, including collateralized loan obligations (CLO), collateralized bond obligations (CBO) and, more generally, CDO. ${ }^{26}$

Insurance-linked securitizations typically transfer certain of a firm's liabilities off its balance sheet into the financial markets. The most common type of security is a catastrophe ("cat") bond. ${ }^{27}$ Cat bonds transform insurance risks (i.e., catastrophe risks) into credit risks. Over the last few years, the structures and characteristics of these types of bonds have become commonplace. Typically, a bankruptcy-remote special-purpose reinsurer (SPR) issues notes to investors while a trustee invests the proceeds from investors and the reinsurance premium from the ceding company to generate the required return. Unless a catastrophic event triggers a payout to the

${ }^{23}$ See Hannover Re (2007). Also see Societe Generale Corporate and Investment Banking (2007).

${ }^{24}$ What makes the transaction "synthetic" is the fact that a number of the 100 companies included do no reinsurance business whatsoever with Hannover Re. Nonetheless, Hannover Re receives a payoff when an adverse credit event impacts these companies.

${ }^{25}$ Some years ago, royalties from recordings by the singer David Bowie were securitized, for instance.

${ }^{26}$ Here is a good example of how the field of financial engineering evolves through clever combinations of different methodologies and techniques. Modeling for asset securitizations and modeling for interest rate derivatives led to the modeling of credit risk. In combination, they make credit derivatives like CDS and credit securitizations like CDO possible. Credit risk models, in turn, led to market risk models; and, with the latter, it is now possible to develop equity derivatives, lately a very rapidly growing segment of the derivatives market.

${ }^{27}$ Cat bonds represent the largest segments of insurance-linked securitizations. Other risk transfer possibilities however exist. See, for example, the trade credit retrocession transaction completed by Gerling Credit Insurance Group in 1999 (see Culp (2006, p. 499)). 
ceding company, the collateral in the SPR is used to cover the principal and interest at maturity.

Since there are no underlying assets being traded, the specific design of an appropriate trigger is essential. A variety of different types of triggers is possible:

- an indemnity trigger activates through actual losses;

- an index trigger is tied to an index usually established by an independent and agreed to third party;

- a parametric trigger activates when a certain level of losses is reached; and

- a "modeled loss" trigger activates when expected losses reach a certain level.

There are trade-offs between each type of trigger. Indemnity triggers entail moral hazard since the size of the claims payout remains within the control of the issuer. Index, parametric, and modeled loss triggers do not entail moral hazard but give rise to basis risk since the payoff released by the trigger may differ from the actual claims payout.

There is a wide latitude for terms as well. Deals can be of a multi-year nature; they can cover single or multiple perils; multiple tranches, each with a different rating and pricing are possible. An ever-increasing base of investors, now including a number of hedge funds, assures liquidity both for initial offerings as well as for the secondary market. Their interest stems from the zero-beta aspect of cat bonds ${ }^{28}$ as well as the relatively higher yields that these instruments offer.

Interest in issuing cat bonds continues. One area of increasing activity is the direct issue of cat bonds by commercial or industrial enterprises. Several new issues appear to be under consideration. ${ }^{29}$

Another form of securitization is the "sidecar". Sidecars are similar to cat bonds. A sidecar is a single-purpose reinsurer through which investors provide additional capacity to an existing sponsor, with investors and sponsor sharing specific risks typically cat risks - in specific proportions. Over 20 of these entities have been formed in the last year or two, with hedge funds committing nearly $\$ 8$ billion to this form of security. While their rate of formation will probably slow down if 2007 is a quiet hurricane year, they are likely to be revived when capacity once again is at issue. ${ }^{30}$

\section{Contingent capital $^{31}$}

Capital markets also offer contingent debt or equity financing triggered by an insurance-related event. The idea is to firm up an insurer's financial condition prior to a major loss and not after, when doing so would be more costly or more uncertain. As with cat bonds, the financing is activated by a trigger. Contingent debt can take a

\footnotetext{
${ }^{28}$ There appears to be little or no correlation between catastrophic events and financial markets.

${ }^{29}$ The Disney Company, via its Oriental Land transaction and Vivendi Universal Studios were the first to do a corporate cat bond transaction. More recently (2006), Dominion Resources securitized its cat exposures in the Gulf of Mexico, the parametric trigger being certain wind speeds.

${ }^{30}$ See Sclafane (2007, pp. 12-13).

${ }^{31}$ For a thorough review of the entire subject matter, see Culp (2006).
} 
variety of different forms. Under a committed capital facility (CCF) a specific debt financing program gets triggered by a loss event. A contingent surplus note (CSN), on the other hand, creates an investment trust funded by investors until the contingent capital gets triggered. Other forms include contingency loans, various financial guarantees, letters and lines of credit and residual value guarantees.

Contingent equity financings usually take the form of loss equity puts (LEP), committed long-term capital solutions (CLOCS), or reverse convertibles. LEPs simply allow for the issuance of privately placed equity through a put option. CLOCS contain elements of both equity and debt by allowing for the placement of structured preferred stock. Reverse convertibles allow for the conversion of debt into equity at a prespecified price.

Quite frankly, contingent capital deals have been rather rare compared to derivatives and securitizations. Nonetheless, there are rumors in the market about a number of these types of deals coming on stream. Often these are private transactions of a standby nature that require little in terms of disclosures. Hence, it is difficult to prognosticate about future trends.

\section{Concluding remarks}

This concludes our update. The market for insurance-linked financial instruments is real. Events such as Hurricane Katrina should eliminate any element of doubt as to the potential strategic value of ILS for firms engaged in insurance and reinsurance. We seem to have moved from thinking of ILS purely in tactical terms such as relative pricing to a more mature evaluation based on business strategies that recognize the value of multiple sources of financing. Good reasons for doing so exist not just for those who are concerned with property catastrophe risks. Reinsurance recoverables, as we have seen, and other major ticket items on balance sheets - indeed every asset and liability - ought to be considered for funding or for transfer into the financial markets. In a global world within instant electronic reach to every investor in financial markets, there is next to no room for any inefficiency in managing one's capital by every means available. That is the challenge. That is also the opportunity.

\section{References}

Aspen Insurance Holdings Limited (2006) Aspen Insurance Holdings Limited announces completion of innovative insurance policy, similar to Credit Default Swap, Press Release (6 December).

Banks, E. (2004) Alternative Risk Transfer: Integrated Risk Management Through Insurance, Reinsurance and the Capital Markets, Chichester, West Sussex: John Wiley \& Sons.

Catlin Group (2006) Catlin participates in innovative natural catastrophe security, Press Release (27 September).

Culp, C.L. (2006) Structured Finance \& Insurance: The ART of Managing Capital and Risk, Hoboken, NJ: John Wiley \& Sons.

Deutsche Bank (2006) Deutsche Bank launches Event Loss Swaps to help clients hedge against disasters, Press Release (30 November).

Financial Times (2007a) Risk management, Financial Times Special Report (1 May).

Financial Times (2007b) Where is all the risk? Leader (3 February).

Hannover Re (2007) Hannover Re securitises insurance recoverables worth around EUR 1 billion, Press Release (26 February). 
ISDA (2007) ISDA publishes year-end 2006 market survey, Press Release (18 April).

Krutov, A. (2006) 'Insurance-linked securities: An emerging class of financial instrument', Financial Engineering News 48(March/April), at www.fenews.com.

Lane, M. (2002) Alternative Risk Strategies, London: Risk Waters Group.

Lumley, B. (2007) 'Curiosity turns to normality', Captive and ART Review (March): 32.

McDonnell, E. (2002) 'Industry loss warranties', in M. Lane (ed) Alternative Risk Strategies, London: Risk Waters Group.

Sclafane, S. (2007) 'Is the sidecar joyride over?', National Underwriter (19 February): 12-13.

Societe Generale Corporate and Investment Banking (2007) Corporate \& Investment Banking launches Merlin $C D O I B V$, the first synthetic CDO of insurance and reinsurance entities, Press Release (26 February).

Steil, B. (2006) 'Derivatives exchanges owe much to wise regulation', Financial Times (28 November).

Swiss Re. (2006) 'Securitization - new opportunities for insurers and investors', Sigma No. 7/2006.

\begin{abstract}
About the Author
Ernst N. Csiszar is the former President and Chief Executive Officer of the Property and Casualty Insurance Association of America. He is also a former insurance regulator for the State of South Carolina and served as President of the National Association of Insurance Commissioners. He graduated from the University of Windsor, Ontario, Canada with a degree in Mathematics and Philosophy. He also holds a Bachelor of Laws degree from that same institution. He has worked in both merchant banking and insurance.
\end{abstract}

